International Journal of Discrimination and the Law, 2007, Vol. 8, pp. 219-236 $1358-2291 / 2007 \$ 10$

(C) 2007 A B Academic Publishers. Printed in Great Britain

\title{
DISABILITY DISCRIMINATION AND IMMIGRATION IN AUSTRALIA
}

\author{
ELIZABETH WALDECK and ROBERT GUTHRIE
}

Curtin University of Technology, Western Australia

\begin{abstract}
In order for an application for migration to Australia to be successful, potential migrants must meet various criteria, including specific requirements relating to health. These health requirements may create a barrier to migration to Australia for those who suffer from disability or disease. The Disability Discrimination Act 1992 (Cth) makes it unlawful to discriminate against a person based on disability, including disease. Significantly, the Disability Discrimination Act 1992 (Cth) does not apply to the Migration Act 1958 (Cth). Therefore discrimination on the grounds of disability in the administration of the Migration Act 1958 (Cth) is lawful. As a consequence of the Migration Act 1958 (Cth) being exempted from the operation of the Disability Discrimination Act 1992 (Cth),-many migration applications have been lawfully refused due to the disability of the applicant or a member of the applicant's family. Recent cases. have tested the validity of the opinions of the Commonwealth Medical Officers who are required to provide the necessary medical opinion upon which the migration application is determined. The decisions of the Federal Court in Robinson and Ramlu, which are discussed below, give new hope to future migration applicants. Both cases were decided in favour of the applicant, holding that the medical opinions provided were invalid under the relevant migration regulations because the Commonwealth Medical Officer had assessed the applicant's disability based upon a hypothetical generic person with the disease or condition of the applicant rather than having regard to the particular circumstances of the applicant. These cases send a clear signal to Commonwealth Medical Officers that they must now provide opinions based upon a case by case analysis, having regard to the actual nature and extent of the applicant's condition, rather than an assessment based on the generic person with the disease or condition. This paper examines these decisions in detail against the background of Australian immigration policy and its effects on people with disabilities.
\end{abstract}

\section{INTRODUCTION}

This paper explores the interaction of migration and disability discrimination laws in Australia. The Migration Act 1958 (Cth) (the Migration $A c t$ ) regulates, inter alia, the arrival and presence in Australia of non-citizens. The Disability Discrimination Act 1992 (Cth) (the DDA) makes unlawful discrimination on the basis of 
physical, intellectual, psychiatric, sensory, and neurological and learning disabilities. The Migration Act is exempted from the DDA, having the effect that it is not unlawful to discriminate on the grounds of disability in the administration of the Migration Act.

This paper is divided into two parts. The first part presents a brief overview of the Migration Act and the DDA, including a discussion of the exemption of the Migration Act from the operation of the DDA and a summary of the Productivity Commission's submission to the government relating to the exemption. The second part of this paper explores the preliminary health requirements to be met by applicants for migration under the Migration Act and focuses on significant cases which have tested the lawfulness of the administrative processes involved in denying entry to Australia of disabled persons. The paper concludes with some suggestions for reform and reflections on the current procedures.

\section{THE MIGRATION ACT 1958 (CTH)}

The Migration Act and its regulations ${ }^{1}$ regulate, inter alia, the arrival and presence in Australia of non-citizens, and the selection criteria and application processes for all visa categories. Except for New Zealanders, migrants must apply for a visa to come to Australia, the acceptance of which is determined by the Department of Immigration and Multicultural and Indigenous Affairs (DIMIA). To obtain a visa, migrants must pass health and character checks and meet certain other entrance criteria. There are two programs aimed at assisting people to migrate to Australia: a humanitarian program and a migration program. The humanitarian program is for refugees or anyone else seeking safety or asylum in Australia. The migration program covers all other persons who are interested in migrating to Australia. There are several categories under which potential migrants can apply for an Australian visa under the migration program. Generally these are:

- skilled migrants - people who have particular occupational skills, outstanding talents or business skills;

- family sponsored migrants - those who are sponsored by a relative who is an Australian citizen or permanent resident;

- special eligibility migrants - former citizens or residents wanting to return to Australia, or certain New Zealanders.

The Migration Act provides that the regulations may prescribe criteria for visas of specified classes. ${ }^{2}$ Regulation $2.25 \mathrm{~A}$ generally provides that in determining whether an applicant satisfies the criteria for the granting of a visa, the Minister must seek the opinion 
of a Medical Officer of the Commonwealth ('MOC') as to whether a person $^{3}$ meets the health requirements of Public Interest Criteria (PIC), at Schedule 4 of the regulations.

A 'MOC' is a medical practitioner appointed in writing by the Minister for the purposes of the regulations. ${ }^{4}$ The Minister is required to accept the opinion of the MOC on referred matters as correct, for the purposes of deciding whether a person meets a requirement or satisfies a criterion. ${ }^{5}$ PIC 4005 sets out the health requirements which are deemed to be satisfied if the applicant:

- is free from tuberculosis; and

- does not suffer from a disease or condition that is or may result in the applicant being a threat to the Australian health system or public; and

- does not suffer from a disease or condition that is such that 'a person' who has it would be likely to require health care or community services, the provision of which would be likely to result in a 'significant cost' to the Australian community ('limb 1'), or prejudice the access of an Australian citizen or permanent resident ('limb 2'), regardless of whether the health care or community services will actually be used in connection with the applicant.

?

According to DIMIA, the health requirements are designed to:

- minimise public health and safety risks to the Australian community;

- contain public expenditure on health and community services, including Australian social security benefits, allowances or pensions; and

- maintain access of Australian residents to health and other community services. ${ }^{6}$

Section 65 of the Migration Act provides that if, after considering a valid application, DIMIA is satisfied that the health criteria have been met, (along with other criteria), then the visa is granted. Likewise if DIMIA is not so satisfied, the visa application is refused. ${ }^{7}$ If the visa application is refused on the basis that one family member does not satisfy the health criteria, the whole family unit will not be allowed to migrate.

If a visa is refused because the applicant does not satisfy the health requirements, the applicant has the right to have the decision reviewed before the Migration Review Tribunal (MRT) ${ }^{8}$ The MRT, like the Minister, is bound to accept as correct the opinion of the MOC on the prescribed matters ${ }^{9}$ however, it is open to the MRT to seek a further opinion from the $\mathrm{MOC},{ }^{10}$ or request a complete review from a Review Medical Officer of the Commonwealth (RMOC). 


\section{DISABILITY DISCRIMINATION LEGISLATION AND INTERNATIONAL CONVENTIONS}

Whilst there exists no binding international treaty with respect to human rights for people with disabilities, the Australian Government fulfilled its obligations under the United Nations Declaration of the Rights of Disabled Persons (1978) ('The Declaration')" in 1992, through the enactment of the DDA, which came into effect in March 1993. The Declaration provides that all individuals with disabilities shall enjoy all the rights set forth in the Declaration and that such rights shall be granted to all disabled persons, without any exception whatsoever and without distinction or discrimination on the basis of race, colour, sex, language, religion, political or other opinions, national or social origin, state of wealth, birth or any other situation applying either to the disabled person himself or herself or to his or her family. ${ }^{12}$ As only certain resolutions of the General Assembly are binding, the Declaration remained recommendatory only, until Australia enacted consistent legislation under the DDA in 1992.

Signature and ratification of an international treaty/convention has no effect on Australian law, as they are acts of the executive, and legislative action is required before any international obligations have any effect on domestic Australian law. ${ }^{13}$ Ratification for the purposes of Australian law involves the decision of the Governor General to ratify the treaty as Head of State and representative of the Queen. The Governor General must also undertake an 'act of deposit' of the instrument of ratification and have the terms of the treaty accepted by the responsible department. That said, in 1995 the High Court of Australia held in Minister for Immigration and Ethnic Affairs $v$. Teoh ${ }^{14}$ that there was a legitimate expectation that the executive and its agencies (e.g. the Commonwealth Public Service) should administer the law having regard to terms of international treaties/conventions which have been ratified, even where the treaty has not been incorporated into Australian legislation. Mason CJ and Deane J (at 290) held that ratification of a convention is a positive statement by the executive government that it will act in accordance with the convention, thus creating a legitimate expectation. As a matter of procedural fairness, a decision maker should have regard to such conventions particularly where the Australian statute or regulations are ambiguous (at 286).

The effects of the decision in Teoh were obviously far-reaching and sparked a flurry of activity at executive level, ultimately resulting in the Administrative Decisions (Effect of International Instruments) Bill 1999 which attempted to override the effect of Teoh. The efforts of the legislature to override the effect of Teoh were heavily criticised 
by a number of commentators. ${ }^{15}$ However the Bill was never passed and Teoh still stands and has recently been cited with approval in the High Court and Federal Court. ${ }^{16}$ It follows that in considering an application for immigration or for a particular visa, an officer of DIMIA should have regard to relevant international conventions even where they have not been the subject of domestic legislation, except where, as in the case of the Migration Act, the legislative intent is to clearly exclude the operation of the DDA.

\section{THE PURPOSE OF THE DDA}

The DDA reflects the Declaration by providing in general terms that discrimination on the basis of disability is unlawful. ${ }^{17}$ Section 3 of the DDA sets out the objects of the Act, which seek to eliminate, as far as possible, direct and indirect discrimination on the grounds of disability, making such discrimination unlawful in a wide range of areas including employment, education, sport, access to premises, accommodation, in the administration of Commonwealth laws and programs and in the provision of goods, services and facilities. When introducing the Bill into parliament, Minister for Health, Housing \& Community Services, Hon Brian Howe, declared:

The Bill recognises that discrimination against people with disabilities is a matter of international concern. It is another significant step in fulfilling Australia's international obligations under a number of United Nations instruments. ${ }^{18}$

\section{SOME KEY PRINCIPLES IN DISABILITY DISCRIMINATION LAW}

Generally speaking, discrimination is any practice that makes distinctions between individuals or groups so as to disadvantage some and advantage others. In Australia, unlawful discrimination can be direct or indirect. Direct disability discrimination occurs when a person with a disability is treated less favourably, by reason of their disability, than a person without the disability would be treated in the same or similar circumstances. ${ }^{19}$ In Hills Grammar School v. Human Rights and Equal Opportunity Commission $^{20}$ (the Hills Grammar School case), the appellant school admitted directly discriminating against a student who suffered from spina bifida, by refusing to enrol her. The school attempted to make out the defence of unjustifiable hardship: that is, that the needs of a child with spina bifida would impose an unjustifiable hardship on the school. The defence failed, thereby 
resulting in unlawful direct discrimination. An important feature of the Hills Grammar School case was that the court determined that it was necessary when considering the issue of unjustifiable hardship, to have regard to the individual needs of the particular student and the costs thereof, rather than considering the possible costs for a hypothetical student with the same medical condition as the applicant.

Indirect discrimination occurs when there is a requirement or condition which applies to everyone, but has an unfair effect on a person or a particular group of persons with a disability, and the requirement is not reasonable, having regard to the circumstances of the case. ${ }^{21}$ For example in Scott v. Telstra Corp Ltd ${ }^{22}$ Telstra had a blanket policy of providing standard handsets for telephones, but refused to provide any alternative telecommunications devices, including teletypewriters, for people with a hearing impairment. Telstra argued that the service it provided was the telephone network and that the provision of handsets was additional to that service. However, the Human Rights and Equal Opportunity Commission found that the service provided was more broadly communication over the network, and that the requirement that the network be accessed by standard handsets was clearly one which a disproportionate number of people with profound hearing loss could not access and which was unreasonable in the circumstances. The refusal to provide those with profound hearing loss with teletypewriters amounted to indirect discrimination. Again the key element of the decision in Scott v. Telstra Corp Ltd was the need to assess the particular needs of the individual applicant, rather than hypothetical needs and costs. It can be observed that the DDA requires the relevant court or tribunal to consider the particular circumstances of each case and the needs of each applicant.

\section{THE EXEMPTION OF THE MIGRATION ACT FROM THE OPERATION OF THE DDA}

As previously noted, the Declaration specifies that individuals with disabilities shall enjoy all the rights as set out therein, without exception. These rights include the right to respect for human dignity, the entitlement to the measures designed to enable disabled persons to become as self-reliant as possible, and the right to medical treatment and associated services which will enable the development of capabilities and skills. The Declaration also states that disabled persons shall be protected against all regulations of a discriminatory nature. Nevertheless, the DDA provides for a total exemption of its provisions in respect of the Migration Act, despite the reference in the 
objects of the DDA making it unlawful to discriminate in the administration of Commonwealth laws. Section 52 of the DDA exempts the Migration Act, all regulations made under the Act and anything done by a person in relation to the administration of that Act from the discrimination provisions of the DDA. Thus, in assessing an application from a potential migrant for entry into Australia, the Migration Act allows for the application to be refused on the basis of a disability, and such refusal is lawful.

\section{THE PRODUCTIVITY COMMISSION'S REVIEW OF THE EXEMPTION OF THE MIGRATION ACT FROM THE OPERATION OF THE DDA}

In 2004, at the request of the Federal Government, the DDA was reviewed by the Productivity Commission (the 'Commission'). The findings of the review were submitted to the Commonwealth Attorney General. ${ }^{23}$ The review made a number of recommendations to improve the effectiveness of the legislation. The majority of the recommendations were accepted by the Government in full, in part, or in principle. Many organisations that represent disabled groups made submissions upon which the Commission commented. ${ }^{24}$ These submissions related largely to the health requirements under the PIC which had to be met by those that applied for entry to Australia. ${ }^{25}$ In relation to the exemption of the Migration Act from the DDA, the Commission reported the following:

If the Migration Act were not exempt from the DDA, these health requirements might conceivably be found to discriminate against some people with disabilities indirectly (by setting rules that they do not or cannot meet), or discriminating directly (by requiring additional tests or medical evidence that are not required of people without disabilities).

Several inquiry participants argued the Migration Act exemption in the DDA is too broad. In particular, they argued that the health requirements for permanent migration have unfairly or unreasonably denied entry to some people with disabilities and their families. Their concerns appeared to relate mainly to the manner in which the health requirements may have been applied, rather than to the existence of the requirements themselves.

The Commission found that whilst the exemption is appropriate, the current scope may be wider than necessary. ${ }^{26}$ In support of participant concerns, the Commission recommended that the exemption be reviewed and amended to ensure it does not exempt administrative processes under the Act and its regulations. ${ }^{27}$ The Government 
did not accept this recommendation on the basis that the existing exemption was necessary and appropriate. The Government's somewhat vague response on this issue was that:

... In assessing whether a visa applicant satisfies the health requirements, it may be necessary to request the applicant to undertake various health examinations and assessments. Such requests are made on a case by case basis, dependent on the specific condition and circumstances of the applicant.

The health requirements and their administration ensure that Australians, including Australians with a disability, continue to receive essential appropriate health and community services. ${ }^{28}$

The undercurrent of this statement is that immigrants with disabilities are a cost to the community and that the expenditure might be more appropriately directed to 'Australians'. However, the cases below show that some applicants with health requirements in fact have an earning capacity and might contribute to their own health costs. Likewise in some cases, families have given an undertaking to underwrite health costs. Addressing this latter issue in a media release on 28 January 2005, the then Acting Disability Discrimination Commissioner, Dr Sev Ozdowski, commented on the Government's decision to retain the existing exemption stating:

We understand the sensitivity of issues in this area for sovereign governments, but we hope that the Government will examine other .ways of ensuring that potential costs to the community arising from migration by people with disabilities are accurately assessed, and that these costs are appropriately balanced against the contribution that people with disabilities and their families can and do make to the community. ${ }^{29}$

\section{THE HEALTH REQUIREMENTS - PRELIMINARY ISSUES UNDER THE MIGRATION ACT}

In making a determination in relation to the health criteria, the MOC must firstly form an opinion as to whether the applicant has a disease or other health condition and then assess objectively whether ' $a$ person' who has such a disease or condition would be likely to require health care or community services that would be 'likely to result in significant cost to the Australian community ('limb $1^{\prime}$ ), or would prejudice access of an Australian citizen' ('limb 2'). This determination is made regardless of whether the applicant will use the health care or community services being assessed as a cost against their disease or condition.

In an important decision on these regulations, Inguanti $v$. Minister for Immigration and Multicultural Affairs, ${ }^{30}$ it was argued 
that PIC 4005 was invalid on the basis that it was illogical and unreasonable to assess the likely costs regardless of whether the care would actually be used. However, holding the regulation to be valid, Heerey $\mathbf{J}$ determined that it was reasonable to expect a $\mathrm{MOC}$ to assess the nature of a disease or condition and its seriousness in terms of its likely future requirement for health care, but not reasonable to expect a MOC to inquire into the financial circumstances of a particular applicant. As discussed below, Heerey $\mathbf{J}$ was more concerned with the process adopted by the MOC in compiling the required medical opinion.

\section{WHAT OBJECTIVE TEST IS USED UNDER PIC 4005?}

Importantly, 'a person' referred to in PIC 4005 is 'not the applicant, but a hypothetical person who suffers from the disease or condition which the applicant has'. "I1 In Inguanti, Heerey $J$ held that the MOC's opinion was not authorised by the regulations because the MOC interpreted PIC 4005 as requiring that the applicant's condition, and not a hypothetical person's condition, would be likely to result in a significant cost to the Australian community. ${ }^{32}$

This aspect of the regulations was reviewed by Finkelstein $\mathbf{J}$ in $X$ v. Minister for Immigration and Multicultural and Indigenous Affairs. ${ }^{33}$ Counsel for the applicant in this case submitted that the criterion under PIC 4005 indicates a broad application, in that the nature and extent of the particular symptoms of the disease or condition suffered by the applicant must be applied to the hypothetical person. In this case the applicant was infected with the Human Immunodeficiency Virus (HIV), but was, according to the examining doctor who provided a report to the $\mathrm{RMOC}$ :

a healthy man on combination treatment for which he pays and will continue to pay while he is the holder of a temporary residence visa... the costs... borne by the Australian health care system for the period of the visa he seeks, that being a period of only four years . . is a total(ly) insignificant cost . . 34

However Finkelstein J, in following Inguanti, agreed with the respondent who submitted that PIC 4005 requires the RMOC to focus upon the position of ' a hypothetical person who suffers from HIV' since, according to Finkelstein $\mathrm{J}$, the terms of the provision focus on the disease or condition generally, not upon the particular condition of the applicant.

According to one commentator, this interpretation of PIC 4005 allows the MOC to ignore the fact that each person experiences HIVAIDS in a different way and that the condition manifests itself in 
such a way as to result in a different cost estimate in each case. ${ }^{35}$ This same analysis might apply to a range of medical conditions such as diabetes, autism and Down's syndrome, which may affect individuals in various ways and which might require a range of interventions or in some cases very few. This approach clearly contrasts with the approach taken in relation to cases determined under the DDA, which requires a tribunal to have regard to the individual's impairment or medical condition, rather than a hypothetical individual with the impairment or medical condition.

\section{WHAT IS 'SIGNIFICANT COST' TO THE AUSTRALIAN COMMUNITY?}

The Minister, in having regard to the MOC's opinion as to whether a person meets the health requirements, must also have regard to the MOC's, opinion as to the likelihood of significant cost to the Australian community. ${ }^{36}$ Interestingly, at first instance in the case of Seligman v. Minister for Immigration and Multicultural Affairs, ${ }^{37}$ Foster J expressed surprise that a MOC is entrusted with the task of assessing the significant costs to the Australian community, rather than to an appropriate member of the DIMIA. ${ }^{38}$ There is no prescribed definition of what costs are to be regarded as significant; but the MOC may be guided by a multiple of average annual per capita health and welfare expenditure for Australians. ${ }^{39}$ On appeal, French, North and Merkel JJ made it clear that as a matter of sound administrative law, the Minister is only entitled and obliged to take the opinion of the MOC as correct, if the opinion is of a kind authorised by legislation. ${ }^{40}$ The facts in Seligman were that the Seligman family applied to migrate to Australia from South Africa under a Senior Executive visa. On all points except for the health of their 22-year-old son Gregory, the Seligman's qualified for the visa. Gregory Seligman had borderline intellectual functioning and despite positive specialist reports as to Gregory's future, an undertaking by his parents to set up a trust fund for his support, an offer of employment in Australia and a Certificate in Personal Computer and Office Skills being held by Gregory, DIMIA refused the visa. The application was refused on the basis of a MOC report which concluded that Gregory's condition would be likely to result in a significant cost to the Australian community in the areas of health care and community services. The MOC prepared the report on the basis of available medical and radiological reports and stated that it would be likely that Gregory's condition would meet 'medical impairment criteria for long term income support in Australia. This would be costly to the taxpayer....' 
Foster $\mathrm{J}$ found in favour of the Seligmans, concluding that there was no apparent evidence before the MOC that Gregory was likely to meet 'the medical impairment criteria for long term income support' as a result of being in receipt of a disability pension, which would result in significant cost to the Australian community. ${ }^{41}$

The case went on appeal to the full court in Minister for Immigration and Multicultural Affairs $v$. Seligman, ${ }^{42}$ with the Minister claiming that the relevant evidence of the medical criteria held by Foster $\mathbf{J}$ as being not apparent, was in fact the psychologist's assessment and various other letters prepared for the MOC. The Full Bench gave consideration to the assessment made by the MOC and in dismissing the appeal stated:

The assessment made by the Medical Officer of the Commonwealth that Gregory would meet medical impairment criteria for long term income support in Australia and that this would be costly to the taxpayer, appears to have been the only link in the chain between his observations as to Gregory's condition and the condition that there was likely to be a significant cost to the Australian community in the area of health care or community services. It is apparent on this basis that he had no regard to the actual likelihood that there would be a significant cost to the Australian community. ${ }^{43}$

In other words the MOC had applied the wrong criteria, which resulted in the opinion being outside the scope of the regulations. The issue of how the MOC should assess significant costs was revisited recently in Robinson $\nu$. Minister for Immigration and Multicultural and Indigenous Affairs. ${ }^{44}$ This decision raises a number of points and is worth considering in detail. The Robinsons, together with their son David who suffered from a mild form of Down's syndrome, underwent medical examinations as part of the visa . application process. DIMIA advised the Robinsons that David did not meet the health requirements as set out in PIC 4005 and that therefore their application was refused.

Additional information was then provided by the applicants that reflected positively upon David's prospects in terms of future employment and level of independence. However a second MOC provided another report (similar to the first), upon which the Robinsons were informed that their appeal was unsuccessful. The decision was reviewed by the MRT. The Tribunal sought a further medical opinion from a Review MOC (RMOC). This opinion supported the previous MOC's opinion; however the RMOC stated:

A person with such a disease or condition would be likely to require health care or community services or would be likely to meet the medical criteria for the provision of a community service and provision 
of such health care or community services relating to the disease or condition would be likely to result in a significant cost to the Australian community in the areas of health care and community services, or prejudice the access of Australian citizens or permanent residents to health care and community services. ${ }^{45}$

Thus whilst the RMOC stated that David's Down's Syndrome was a disease or condition to which the 'first limb' of PIC 4005 applied, the RMOC then went on to also apply the 'second limb' to David, in that David's condition would prejudice the access of an Australian citizen to health care or community services. The RMOC did not specify on what basis the 'first limb' applied to David, and made no mention as to the health care or community services that David would prejudice access to for an Australian citizen when referring to the 'second limb'.

A further medical opinion from the RMOC was sought by the MRT who also requested that the RMOC provide information with respect to what material the $\mathrm{RMOC}$ had considered in forming the opinion. The RMOC replied, stating that the opinion was based on 'available medical and radiological reports and the proposed duration of stay sought in Australia'. Once again the RMOC stated that both limbs of PIC 4005 applied to David without any evidence in support of the second limb.

At the hearing before the MRT, Robinson's counsel submitted that the MRT was not bound to accept the opinion of the RMOC as correct, as the opinion was not one authorised by the regulations. Further it was argued that PIC 4005 required the MOC to assess the specific nature and extent of David's condition and then apply the statutory criteria, namely the costs to the Australian community of the hypothetical person having that specific condition. The Tribunal however, found that it was bound to accept the RMOC's opinion as correct and had no authority to disregard it.

The matter went on appeal to the Federal Court of Australia. Justice Siopis found in favour of the Robinsons, holding that the MRT had made a jurisdictional error by relying upon an RMOC opinion that was clearly invalid, because it failed to ascertain and consider the actual nature and extent of David's level of impairment. Siopis $J$ explained that both the MOC and RMOC are required by law to ascertain the exact form or level of disease or condition suffered by a visa applicant, and then assess whether the provision of health care or community services to a hypothetical person with that level of disease or condition would result in a significant cost to the Australian community. Siopis $\mathbf{J}$ found that the RMOC had failed to properly consider the level of David's Down's syndrome when forming an opinion. The RMOC's opinion made no reference to the fact that the level of David's Down's syndrome was 'mild', making reference only to a generic form of the condition. 
ir contralian zes, or ints to

ne was a lied, the Javid, in ustralian ot specify iention as prejudice ind limb'. iht by the ormation n forming was based proposed e $\mathrm{RMOC}$ thout any

submitted RMOC as zgulations. to assess then apply ommunity ition. The e RMOC's

Australia. ng that the an RMOC certain and mpairment. required by $r$ condition re provision person with nificant cost RMOC had 's syndrome no reference ? was 'mild', in.
Significantly, Siopis J pointed out that Parliament, in the drafting of the regulations, specified tuberculosis as the only disease which would preclude a potential migrant entry to Australia, indicating that Parliament intended the assessment made under PIC 4005 to be made on a case by case basis by reference to the form or level of the disease or condition actually suffered by the applicant. ${ }^{46}$

The principle in Robinson was adopted in Ramlu $v$. Minister for Immigration and Anor. ${ }^{47}$ In Ramlu, the RMOC assessed an applicant who suffered from both arthritis and diabetes. In forming an opinion, the RMOC stated that the applicant did not satisfy PIC 4005. Counsel for the applicant submitted that medical reports supplied to the RMOC indicated that the diabetes was under control and the arthritis was being effectively managed. Additionally, the reports indicated a low level of severity of both conditions and no indication of renal disease. Nevertheless the RMOC considered that the applicant was in the position of a person who had increased functional disability likely to require joint replacement surgery in view of the arthritis and diabetes complicated by hypertension and probable renal disease. Counsel also submitted that the RMOC had incorrectly applied PIC 4005 in failing to provide specific reference to which of the two conditions suffered, or whether both of them, would result in significant cost to the Australian community or prejudice the access of Australians to health or community services.

The bare recitation of the criteria without reference to the diseases or conditions suffered by the applicant or a person in the position of the applicant, or to the nature or extent of cost upon the community, indicates... constructive failure. ${ }^{48}$

Driver FM accepted the opinion of the RMOC with respect to the arthritis, but found that the RMOC failed to assess the diabetes in accordance with PIC 4005; namely to determine the exact nature and extent of the diabetes suffered by the applicant before applying the objective test. Driver FM stated:

... there is no identification of whether Mr Ramlu suffers from type 1 (infantile) or type 2 (late onset) diabetes, which a brief survey of public health information indicates would be important to a consideration of the complexity and cost of ongoing management of the disease. The report of Dr Chen dated 13 October 2002 states that Mr Ramlu has no family history of diabetes and had suffered from the disease for three years. This suggests that Mr Ramlu suffers from type 2 (late onset) diabetes, which public health information indicates can be effectively controlled by drug therapy and lifestyle management. ${ }^{49}$

Driver FM also referred to the RMOC's opinion regarding the renal disease, stating that there was no evidence to support that opinion and that it was therefore unlikely to be taken into account in terms 
of the first limb of PIC 4005. Additionally, Driver FM stated that the RMOC was not clear as to which disease was the one to which the public criteria related and that significantly, the MRT did not consider this in taking the opinion of the RMOC as correct, thus resulting in a jurisdictional error. As a result, Driver FM found in favour of the applicant and remitted the matter to the MRT for redetermination according to law.

\section{APPLICATIONS FOR MIGRATION FROM PEOPLE LIVING WITH HIV/AIDS}

The manner in which the medical opinions of MOCs and RMOCs have been formed has been the subject of comment by Papadopoulos, particularly with respect to the difficulties faced by those applicants who suffer from HIV/AIDS. According to Papadopoulos, these diffculties are exacerbated by the fact that MOCs have generally been of the opinion that People Living With HIV AIDS (PLWHAs) do not meet the applicable health criteria as set out in Schedule 4, since, depending on their condition and length of stay, they are likely to present a significant cost to the community in terms of health care and/or community services. ${ }^{50}$

To date, almost all MOC and RMOC opinions provided in relation to PLWHAs seeking permanent residence have specified that it would cost in the order of $\$ 240,000$ to treat a PLWHA over their lifetime in Australia. This generic lifetime cost estimate makes no specific reference to various factors that would ordinarily determine a PLWHA's lifetime treatment costs. PLWHAs, their partners, families, treating health care professionals and state and national HIV/AIDS organisations have argued for some time that this estimate of $\$ 240,000$ is over-inflated and too generatised. DIMIA has maintained that this estimate is correct, being based upon an understanding that all PLWHAs will require the same treatment. However, Papadopoulos asserts the decision in Robinson has farreaching implications for PLWHAs seeking either temporary or permanent residence in Australia. Based on Robinson, the opinion of an MOC or RMOC in relation to a PLWHA can only be valid where it ascertains the exact nature of the PLWHA's condition and impairment and provides a cost assessment accordingly.

\section{DISCUSSION AND CONCLUSIONS}

Australia has continued to have regard for international conventions and has been a signatory to a range of anti-discrimination declarations. 
t the

1 the

not

thus

id in

or re-

10Cs

sulos,

cants

diffi-

sen of

o not

since,

ely to

I care

led in :cified I over nakes detertners, tional t this IMIA on an tment. is farary or pinion \& valid Idition

entions ations.
In particular, Australia has embraced the Declaration of the Rights of Disabled Persons by enacting the DDA. However, exemption of the Migration Act from the operation of the DDA allows DIMIA officials to discriminate against applicants with disabilities, on the grounds that they might put the Australian health system and economy as a whole to expense. This exemption also allows DIMIA officials to side-step the effects of the High Court decision in Teoh noted above, in that applicants would be precluded from arguing any legitimate expectation that the Declaration could be used to guide the determinations of DIMIA, because of an express statutory prohibition on doing so. In this sense the exclusion of the operation of the DDA upon the administration of the Migration Act is offensive to international and humanitarian laws.

In applying the relevant provisions of the Migration Act, it is clear that some families may suffer hardship by reason of this exemption. The cases above are examples of applicant families who were able to have their cases reconsidered due to jurisdictional error on the part of the Commonwealth Medical Officers. As those cases show, the applicants attempted to mitigate against the potential costs to the Australian health system by giving undertakings to pay those costs. It may be that the Migration Act should be amended to allow applicants to make a case that even if an applicant's disability may be a potential cost to the Australian community, the applicant has the means to reduce or defray those costs. Of course the difficulty for DIMIA in such cases might be the proper assessment of the applicant's means and the reliability of the undertakings.

It is also noted that there exists a contrast between the means by which cases are assessed under the Migration Act and the DDA. It is clear the DDA requires that the individual costs of the applicant be considered, in so far as any adjustments which need to be made for that applicant are concerned. Under the Migration Act, the individual is medicalised and is assessed in the first instance in relation to detection of the nature and extent of any disability; the costs of that disability to the Australian community are then calculated against a hypothetical individual. It would be more appropriate to require DIMIA to attempt to calculate the costs of the applicant's health care based upon the known individual medical requirements. Whilst this would, of course, require some projections and assumptions of costs, at least the result might bear some resemblance to the actual requirements of an applicant who has a disability. Likewise, as noted by several judges, it appears inappropriate for the MOC to make calculations as to medical costs and the like, when this should more appropriately be in the hands of DIMIA who could obtain advice from the MOC and other competent sources. 


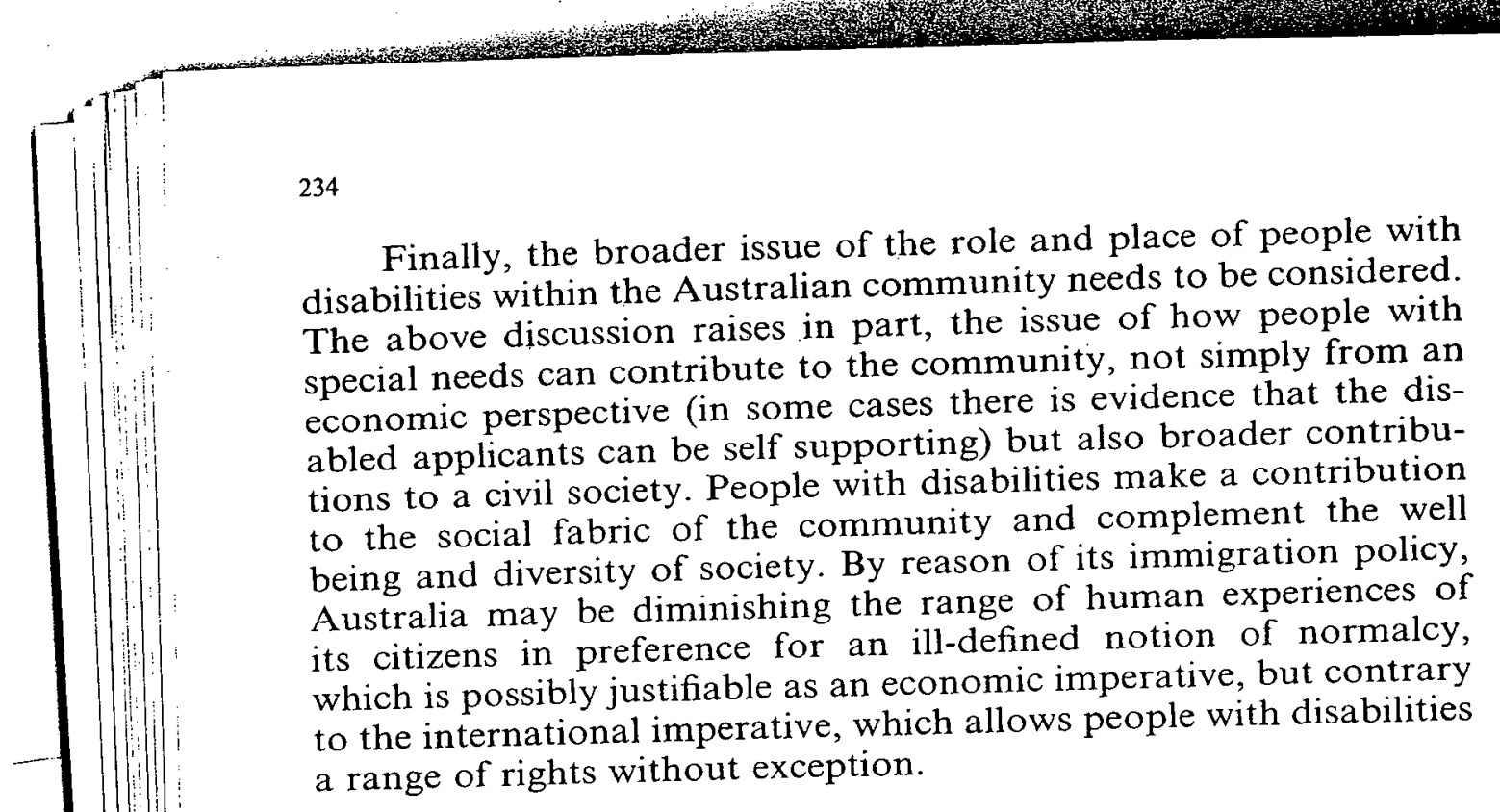

\section{NOTÉS}

1 Migration Regulations (1994).

2 Section 31(3).

3 Dependants and family members who are included in the visa application are individually required to satisfy these requirements. If the application is for permanent residency in Australia, not only do those included in the visa application have to meet the health requirements, but also, all members of the immediate family who do not intend to migrate must meet the health requirements.

4 Reg 1.16AA.

5 Reg 2.25A(3).

6 DIMIA Fact Sheet at www.imi.gov.au/media/fact.sheet/22health.htm last visited 6 August 2006.

7 Section 65 .

8 Regulation 1.03 .

9 Migration Act ss 341(2), 341(4), 349(2), 349(4).

10 Reg 5.41.

11 Proclaimed by the UN General Assembly on 9 December 1975. The Commonwealth Parliament lacks specific power to legislate regarding human rights, disability or discrimination. It does have power over external affairs however, which includes legislating to implement treaties and on matters of international concern.

12 The declaration is attached to the Human Rights and Equal Opportunity Commission Act 1986 (Cth) at Schedule 5.

13 See Attorney General for Canada v. Attorney-General for Ontario [1937] AC 326 at 347 and applied in Minister for Immigration and Ethnic Affairs v. Teoh per Mason and Deane at para 25.

14 (1995) 183 CLR 273.

15 See for example W Lacey (2001) 'In the Wake of Teoh: Finding an Appropriate Government' Response, Federal Law Review 9 and J 
ith

ed.

ith

an

lis-

bu-

ion

vell

icy,

; of

lcy,

ary

ities

lica-

$f$ the

y do

juire-

) not

a.htm

;. The

arding

$r$ over

lement

rtunity

- [1937]

Ethnic

ling an and $\mathbf{J}$
Chen (1995) 'Taking International Treaties More Seriously'. Paper for the Australasian Law Teacher's Association 50th Anniversary Conference but note the contrary view that there is a need for Parliament to make clear the interaction of domestic and international laws in G Cranwell (2001) "Treaties and Australian Law - Administrative Discretions, Statutes and the Common Law', Queensland University of Technology Law and Justice Journal 5.

16 See for example Kontech $v$. Minister for Immigration \& Multicultural Affairs [2006] FCA 508 and Re Minister for Minister for Immigration \& Multicultural Affairs; Ex Parte Lam [2003] HCA 6.

17 The DDA at s 4 provides a comprehensive definition of the term 'disability', so as to include those who currently have a disability, those who previously had, but no longer have a disability, those for whom a disability may exist in the future (e.g., being a member of a family which has a history of heart disease) and those to whom a disability is imputed (e.g., assuming that a gay man has AIDS when he is in fact quite healthy).

18 Hansard (HR) 26 May $19922723-4094$ at page 2751.

19 Section 5 of the DDA.

20 [2000] EOC 93-081.

21 Section 6 of the DDA.

22 [1995] EOC 92-717.

23 Productivity Commission Inquiry Report, Volume 1: Chapters, Report No. 30, 30 April 2004 ('Review of the DDA 1992').

24 These include submissions from HREOC, Blind Citizens Australia, Disability Council of NSWETC. See report at www.pc.gov.au/ inquiry/dda/finalreport/ddl.pdf and dda2.pdf at appendix G1.

25 See this paper at section 'The Health Requirements under the Migration Act'.

26 At finding 12.2 of Review.

27 At Recommendation 12.3 of Review.

28 Productivity Commission Inquiry Report pages 344-345.

29 'Commitment to improve Disability Discrimination Act welcomed' at www.hreoc.gov.au last visited 6 August 2006.

30 [2001] FCA 1046.

31 Heerey $\mathrm{J}$ in Imad v. Minister for Immigration and Multicultural Affairs [2001] FCA 1011 at 13.

32 Imad v. Minister for Immigration and Multicultural Affairs [2001] FCA 1011 at 11 .

33 [2005] FCA 429.

34 Finkelstein J [2005] FCA 429 at 11.

35 ABC Radio National, The Law Report; 'Visa and Health Status' 6 December 2005.

36 Minister for Immigration and Multicultural Affairs v. Seligman [1999] FCA 117 at 2.

37 [1998] 346 FCA.

38 Ibid. at 10.

39 DIMIA Procedures Advice Manual 3 at item 94. 
